\title{
Standard immunohistochemistry efficiently screens for anaplastic lymphoma kinase rearrangements in differentiated thyroid cancer
}

\author{
Gahee Park 1,5,", Tae Hyuk Kim 2,", Hae-Ock Lee', Jung Ah Lim ${ }^{2,6}$, Jae-Kyung Won ${ }^{3}$, \\ Hye Sook Min ${ }^{3}$, Kyu Eun Lee ${ }^{4}$, Do Joon Park ${ }^{2}$, Young Joo Park ${ }^{2}$ and Woong-Yang Park ${ }^{1,5,7}$ \\ ${ }^{1}$ Samsung Genome Institute, Samsung Medical Center, 50 Irwondong, Gangnamgu, Seoul 135-710, Korea \\ Departments of ${ }^{2}$ Internal Medicine, ${ }^{3}$ Pathology ${ }^{4}$ Surgery, and ${ }^{5}$ Biomedical Sciences, Seoul National University \\ College of Medicine, Seoul, Korea \\ ${ }^{6}$ Department of Internal Medicine, Eulji University School of Medicine, Eulji General Hospital, Seoul, Korea \\ ${ }^{7}$ Department of Molecular Cell Biology, Sungkyunkwan University School of Medicine, Suwon, Korea \\ *(G Park and T H Kim contributed equally to this work)
}

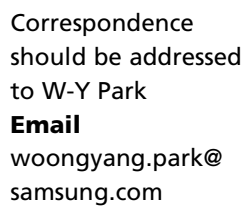

\begin{abstract}
The anaplastic lymphoma kinase $(A L K)$ gene is frequently rearranged in various types of cancer and is highly responsive to targeted therapeutics. We developed a system to detect rearrangement of $A L K$ in a large group of Korean thyroid cancer patients. We screened 474 malignant or benign thyroid tumor cases to identify $A L K$ fusions. Expression and translocation of the $A L K$ gene were analyzed by immunohistochemistry (IHC), fluorescence in situ hybridization (FISH), and digital multiplexed gene expression (DMGE) analysis in formalinfixed paraffin-embedded tissues. Four cases of rearrangement of $A L K$ were detected by IHC, and these cases were validated with FISH on 189 samples. On the other hand, DMGE analysis using Nanostring detected three out of four IHC-positive cases. Two rearrangements of $A L K$ were striatin (STRN)-ALK fusions, which were identified by $5^{\prime}$ RACE analysis. Rearrangements of $A L K$ were found exclusively in v-raf murine sarcoma viral oncogene homolog $\mathrm{B}$ (BRAF) WT papillary carcinomas. Given the wide availability and accuracy of IHC for detecting ectopic expression of ALK in the thyroid, we suggest that IHC-based screening can be a practical method for identifying patients with $A L K$ rearrangements in differentiated thyroid cancer.
\end{abstract}
Key Words
- thyroid cancer
- ALK
- gene rearrangement
- immunohistochemistry

\section{Introduction}

Differentiated thyroid cancer (DTC) is a common endocrine malignancy, and its prevalence is increasing worldwide (Chen et al. 2009). The majority of patients with DTC have favorable outcomes after standard therapy that combines surgery, radioactive iodine ablation, and thyroid-stimulating hormone suppression. Nonetheless, in approximately $30 \%$ of these treated DTC patients, tumors persist or recur (Mazzaferri \& Kloos 2001).
In a recent analysis, the DTC cohorts with structurally incomplete response to the initial therapy were found to have a 10-year survival that approached only $50 \%$ (Vaisman et al. 2011). As these patients were more likely to have ${ }^{18} \mathrm{~F}$-fluorodeoxyglucose positron-emissiontomography-positive and non-radioactive-iodine-avid disease, the current National Comprehensive Cancer Network guidelines recommend the use of small-molecule

Published by Bioscientifica Ltd. 
kinase inhibitors for treatment, given the limited efficacy of cytotoxic chemotherapy (http://www.nccn.org/ professionals/physician_gls/pdf/thyroid.pdf; accessed 26th April 2014).

Identification of the mutations driving DTC prompted the therapeutic use of oral multikinase inhibitors such as sorafenib, which targets rearranged during transfection (RET), v-raf murine sarcoma viral oncogene homolog B (BRAF), and vascular endothelial growth factor receptor (Brose et al. 2014). More recently, rearrangements of anaplastic lymphoma kinase $(A L K)$ that lead to both ectopic expression and constitutive activation of the ALK fusion protein were reported in DTC and anaplastic carcinoma (Godbert et al. 2014, Kelly et al. 2014). Treatment with clinically available ALK inhibitors, such as crizotinib and TAE684, yielded in vitro antitumor efficacy (Kelly et al. 2014) and produced clinical improvement in anecdotal cases (Demeure et al. 2014, Godbert et al. 2014).

To introduce these ALK inhibitors for the clinical treatment of thyroid cancer, the precise frequency of the $A L K$ rearrangement in a wide range of thyroid tumors should be evaluated first. More importantly, a practical diagnostic assay for identifying rearrangements of $A L K$ in thyroid cancer is essential. As is the case with non-small cell lung cancer (NSCLC), immunohistochemistry (IHC) may be a useful tool for screening for rearrangements of $A L K$ in thyroid cancer, as the expression of $A L K$ is extremely limited during adulthood and occurs only in cancer tissues following chromosomal rearrangement (Mino-Kenudson et al. 2010, Shaw et al. 2013).

In this study, we performed comprehensive screening for rearrangements of $A L K$ in a large group of paraffinized thyroid tumor samples using IHC with an ALK-specific antibody. We then confirmed that the expression of ALK protein observed was concordant with rearrangement of $A L K$ using fluorescence in situ hybridization (FISH) and digital multiplexed gene expression (DMGE) analysis. In addition, we reported the discovery of a striatin (STRN)$A L K$ gene rearrangement in a solid variant, the aggressive histological subtype, and the clinicopathological characterization of $A L K$-rearranged papillary carcinoma.

\section{Subjects and methods}

\section{Case selection}

This study included 474 formalin-fixed paraffin-embedded (FFPE) samples from patients with benign and malignant thyroid tumors collected from 1993 to $2002(n=256)$ and from 2010 to $2012(n=218$; Table 1$)$. The samples were collected using a protocol approved by the Institutional Review Board Committee of Seoul National University Hospital.

Two cores of 2.0-mm tissue were obtained from the most representative area of the individual cases, and a tissue microarray block was constructed as described previously (Garcia-Gonzalez et al. 2005). The $B R A F^{\mathrm{V} 600 \mathrm{E}}$ mutation was prescreened in samples of papillary carcinomas using the PCR, restriction fragment length polymorphism analysis, and direct sequencing. We also included 29 matched fresh-frozen samples of WT BRAF papillary carcinoma for detailed genomic analysis. Medical records of the cases with $A L K$ rearrangements were reviewed to extract data including demographic characteristics, histological subtype, tumor-nodes-metastases (TNM) staging according to the Seventh American Joint Committee on Cancer (Edge et al. 2010), and clinical course.

Table 1 Summary of study samples screened for rearrangement of $A L K$

\begin{tabular}{|c|c|}
\hline Histology & Sample type \\
\hline \multicolumn{2}{|l|}{ Papillary carcinoma } \\
\hline WT $B R A F$ & $\begin{array}{l}\text { Fresh-frozen and FFPE } \\
\text { FFPE }\end{array}$ \\
\hline$B R A F^{\mathrm{V} 600 \mathrm{E}}$ mutant & FFPE \\
\hline Follicular carcinoma & FFPE \\
\hline Hurthle cell carcinoma & FFPE \\
\hline Anaplastic carcinoma & FFPE \\
\hline \multicolumn{2}{|l|}{ Benign thyroid tumor } \\
\hline Follicular adenoma & FFPE \\
\hline Hurthle cell adenoma & FFPE \\
\hline Total & \\
\hline
\end{tabular}

ALK IHC

\begin{tabular}{c} 
ALK FISH \\
\hline Positive $(n)$ \\
\hline
\end{tabular}

\begin{tabular}{cc}
\hline \multicolumn{2}{c}{ ALK Nanostring } \\
\hline Positive $(n)$ & Total $(n)$ \\
\hline
\end{tabular}

FFPE, formalin-fixed paraffin-embedded; ND, not done.

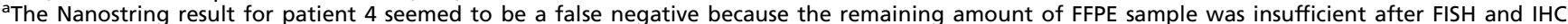
analyses.

http://erc.endocrinology-journals.org DOI: 10.1530/ERC-14-0467
(C) 2015 Society for Endocrinology Printed in Great Britain
Published by Bioscientifica Ltd. 


\section{Immunohistochemistry}

IHC staining was performed in FFPE tissue microarray sections that were $4 \mu \mathrm{m}$ thick using an automated immunostainer (Leica Microsystems, Milton Keynes, UK). Briefly, the slides were heated for $20 \mathrm{~min}$ at $100{ }^{\circ} \mathrm{C}$ in Epitope retrieval solution, $\mathrm{pH} 9.0$ (Leica Microsystems). The slides were then incubated with a monoclonal mouse anti-human ALK antibody (Novocastra, Newcastle Upon Tyne, UK) at a dilution of 1:25. This antibody was raised against a C-terminal portion of the tyrosine kinase domain of ALK and was intended for the qualitative identification of ALK molecules in paraffin sections by light microscopy. Staining intensity was scored as 0 (no staining), $1+$ (weak cytoplasmic staining without any background staining), and $2+$ (strong cytoplasmic staining). Tumors with $1+$ or $2+$ expression in more than $10 \%$ of the tumor cells were deemed positive for ALK protein expression (Yi et al. 2011, Park et al. 2012). For ALK IHC-positive cases, we subsequently performed IHC using an antibody against phosphorylated ALK (phosphor Y1507, Abcam, Cambridge, MA, USA) at a dilution of 1:100.

\section{Fluorescence in situ hybridization}

ALK rearrangements in FFPE tumor tissues were detected by FISH analysis using a break apart probe specific for the ALK locus (Vysis, Abbott Molecular), according to the manufacturer's instructions. Cases were defined as positive by FISH when tumors harbored split signals in more than $15 \%$ of cells or an isolated red $\left(3^{\prime}\right)$ signal in tumor cells as described previously (Kim et al. 2013, Kelly et al. 2014).

\section{RNA isolation from FFPE and fresh-frozen samples}

Six sections from archived FFPE blocks were used for RNA extraction using a High Pure FFPE RNA Isolation kit (Roche). AllPrep DNA/RNA Minikit (Qiagen) was used for RNA isolation from the fresh-frozen biopsy samples. The extracted RNA was quantified and its quality was assessed using a Nanodrop 8000 (Thermo Scientific, Waltham, MA, USA) and a Bioanalyzer 2100 (Agilent, Santa Clara, CA, USA).

\section{5' RACE}

To determine the N-terminal ALK partner, a SMARTer RACE cDNA Amplification Kit (Clontech) was used according to the manufacturer's instructions (Supplementary Fig. 1, see section on supplementary data given at the end of this article). Touchdown PCR was performed using LA HS Taq DNA polymerase (Clontech) with the following primers: $A L K$-gene-specific primer 1 (5'-CCGCCATGAGCTCCAGCAGGATGAAC-3'), Universal Primer A Mix, ALK-gene-specific primer 2 (5'-CAGGGCTTCCATGAGGAAATCCAGT-3'), and Nested Universal Primer A. Amplified products were ligated into the pGEM-T easy Vector (Promega) and subjected to nucleotide sequencing (Macrogen, Seoul, Korea).

\section{RT-PCR for STRN-ALK}

To verify the presence of STRN-ALK fusion transcripts, cDNA was synthesized from total RNA of fresh-frozen and FFPE samples using the ReverTra Ace qPCR RT Kit (Toyobo, Osaka, Japan). The PCR was performed with 35 cycles of denaturation at $94^{\circ} \mathrm{C}$ for $30 \mathrm{~s}$, annealing at $60^{\circ} \mathrm{C}$ for $1 \mathrm{~min}$, and elongation at $72{ }^{\circ} \mathrm{C}$ for $1 \mathrm{~min}$. The specific fusion primers for $S T R N-A L K$ were as follows: STRN exon 3 forward primer (5'-CGGGACAGAATTGAATCAGG-3') and $A L K$ exon 20 reverse primer $\left(5^{\prime}\right.$-TGCCAGCAAAGCAGTAGTTG-3').

\section{Nanostring nCounter analysis}

According to the manufacturer's instructions (Nanostring Technologies, Inc., Seattle, WA, USA), the nCounter assay was performed in order to confirm potential 'fusion calls' in a total of 32 FFPE samples of papillary carcinoma. In brief, $200 \mathrm{ng}$ of total RNA from FFPE and selected freshfrozen samples were hybridized to nCounter reporter probe sets (Supplementary Table 1 and Supplementary Fig. 2, see section on supplementary data given at the end of this article) for $16 \mathrm{~h}$ at $65^{\circ} \mathrm{C}$. The hybridized samples were transferred to the nCounter Sample Prep station, and the reporter signals were visualized using a digital analyzer and normalized using the nSolver analysis software version 1 . The background threshold was calculated from negative controls for a potential 'fusion call'. The calculation was performed as follows: $A L K 3^{\prime} / 5^{\prime}=E_{3} / \mathrm{Max}$ $\left(A_{5}, B\right)$, where $E_{3}$ is the geometric mean of $A L K 3^{\prime}$ probe expression, $A_{5}$ is the average of $A L K 5^{\prime}$ probe expression, and $B$ is the background threshold as defined previously (Lira et al. 2013, Fang et al. 2014). The thresholds for RET and fusion probes were calculated in a similar manner as described previously (Lira et al. 2013, Fang et al. 2014).

\section{Results}

\section{Identification of STRN-ALK fusion in fresh tissue samples}

To search for $A L K$ rearrangements in thyroid cancer, we first examined FFPE samples from 29 cases of papillary

Published by Bioscientifica Ltd. 
carcinoma with WT BRAF that also had fresh frozen tissue available. Of these, one case (patient 1) showed strong cytoplasmic staining for ALK by IHC (Fig. 1A), indicative of abnormal expression due to rearrangment of $A L K$. The break apart FISH assay confirmed rearrangement of $A L K$ through visual splitting of one pair of red and green signals (Fig. 1B). The remaining 28 samples exhibited fused signals (Fig. $2 \mathrm{H}$ ), indicating normal $A L K$ status.

We then performed $5^{\prime}$ RACE to identify the $A L K$ fusion partner in both fresh-frozen and FFPE samples from patient 1 . As shown in Fig. 1C, exon 3 of $S T R N$, was fused with exon 20 of $A L K$, generating a STRN-ALK fusion. The fusion was further verified by RT-PCR with specific primers for $5^{\prime}-S T R N$ and $3^{\prime}-A L K$ (Fig. 1D). This fusion event has been reported recently in a study that examined gene rearrangements in thyroid cancer by paired-end RNA sequencing (Kelly et al. 2014).

\section{Patient screening using ALK IHC in archival paraffinized samples}

To determine the frequency of rearrangements of $A L K$ in thyroid tumors, we screened a tissue microarray of FFPE samples archived from 1993 to 2002. The samples consisted of 123 papillary carcinomas (44 BRAF WT, 79 $B R A F^{\mathrm{V} 600 \mathrm{E}}$ mutants), 25 follicular carcinomas, nine Hurthle cell carcinomas, 17 anaplastic carcinomas, and 82 benign thyroid tumors (Table 1). A positive result for ALK screening by IHC was not obtained for any of these cases. To enrich for ALK-positive cases, the array of BRAF WT papillary carcinomas archived consecutively from 2010 to 2012 was further screened. Among the 189 FFPE samples, three cases showed cytoplasmic ALK localization in IHC (Fig. 2). ALK FISH was performed on those 189 FFPE array samples including the three samples that were positive for ALK by IHC. The results showed break apart or isolated red $\left(3^{\prime}\right)$ signals for only these three, corroborating the results for IHC (Fig. 2). The 5' RACE analysis of the FFPE samples revealed one additional case (patient 2) with an STRN-ALK rearrangement but failed to determine specific fusion partners for the remaining two cases.

Subsequent IHC using an antiphosphorylated ALK antibody revealed activated expression of ALK protein in the four cases with rearranged $A L K$ (Supplementary Fig. 3, see section on supplementary data given at the end of this article). As thyroid cancer commonly harbors RET/PTC translocations (Schlumberger 1998, Nikiforov $\&$ Nikiforova 2011), we also performed RET FISH on the $A L K$-rearranged cases; however, no rearrangements of RET were detected (data not shown), indicating exclusiveness. The overall frequency of rearrangements of $A L K$ was $1.5 \%$ in the BRAF WT papillary carcinoma samples (four of 262). Other types of thyroid cancer, including $B R A F^{\mathrm{V} 600 \mathrm{E}}$ mutant papillary carcinoma and benign thyroid tumors, did not harbor the $A L K$ rearrangement.

\section{Comparison between Nanostring and FISH for the detection of rearrangement of $A L K$}

To explore an alternative screening method for the detection of $A L K$ rearrangement, we employed the Nanostring nCounter assay (Suehara et al. 2012). This assay allows simultaneous detection of multiple translocations using limited amounts of archival paraffinized samples. For parallel comparison with other methods, a total of 32 FFPE samples of BRAF WT papillary carcinoma cases, including the four $A L K$-rearranged cases identified by IHC/FISH, were subjected to the Nanostring assay (Table 1). Using multiplexed probes to target either the $5^{\prime}$ or the $3^{\prime}$ exons of $A L K$, we assessed the $3^{\prime} / 5^{\prime}$ exon
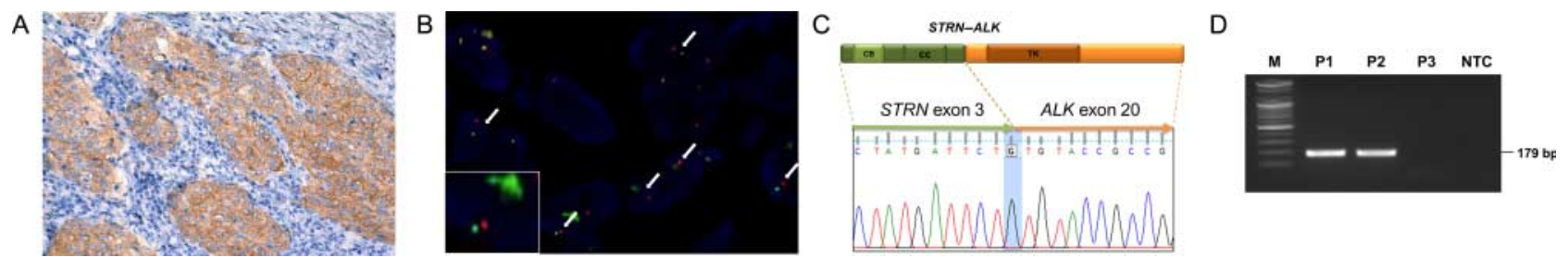

\section{Figure 1}

STRN-ALK fusion in patient 1 with solid variant papillary carcinoma. (A) Photomicrograph image of IHC using the anti-ALK antibody showing strong cytoplasmic staining (magnification: $200 \times$ ). Confirmation of the STRN-ALK fusion by (B) FISH using the break apart ALK probe to show splitting of one pair of red and green signals (arrows) and by (C) nucleotide sequencing, which is accompanied by a schematic presentation of the STRN-ALK rearrangement. The fusion occurred between the ALK

http://erc.endocrinology-journals.org DOI: 10.1530/ERC-14-0467
(C) 2015 Society for Endocrinology Printed in Great Britain
C-terminal intracellular portion, which contains the tyrosine kinase (TK) domain, and the N-terminal portion of STRN, which contains the caveolin-binding domain (CB) and the coiled coil domain (CC). (D) Results for fusion-specific RT-PCR for STRN-ALK (S3; A20, 179 bp). M and NTC indicate the size marker (100 bp ladder) and the non-template control respectively. $\mathrm{P} 1-3$ indicates patients $1-3$. A full colour version of this figure is available via http://dx.doi.org/10.1530/ERC-14-0467.

Published by Bioscientifica Ltd. 

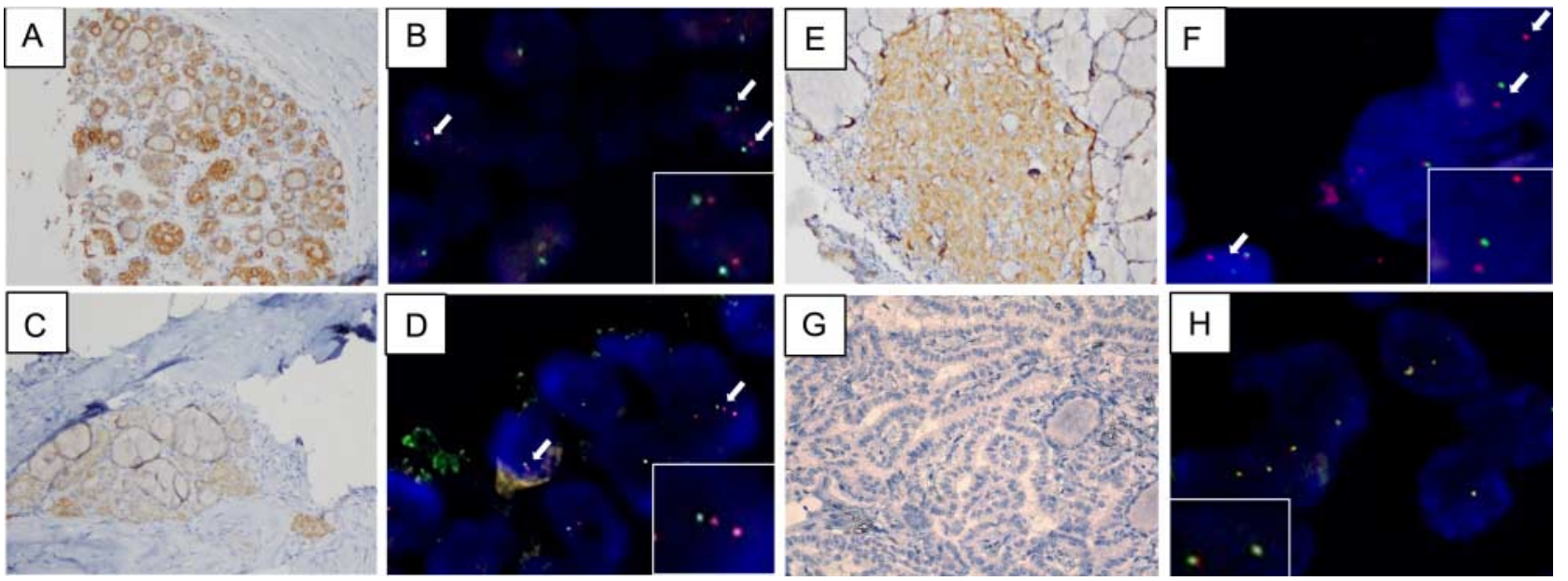

Figure 2

Photomicrograph image of ALK IHC and FISH for patient 2 (A and B), patient 3 ( $C$ and $D)$, patient 4 ( $E$ and $F)$, and a representative patient with native $A L K$ and BRAF genes as a control ( $G$ and $\mathrm{H})$. IHC showed strong cytoplasmic staining in the tumor cells of patient 2 (A) and weak staining in

patients $3(\mathrm{C})$ and 4 ( $\mathrm{E}$; magnification: $100 \times)$. White arrows indicate the split red and green signals that are indicative of $A L K$ rearrangement. A full colour version of this figure is available via http://dx.doi.org/10.1530/ ERC-14-0467.

imbalance. With a $3^{\prime} / 5^{\prime}$ ratio of greater than two as a cut-off, three samples were deemed positive for $A L K$ rearrangements. One discordant result (positive by IHC/ FISH and negative by Nanostring) was obtained for patient 4 , and this sample included an insufficient amount of RNA due to a limited quantity of sample, indicating that the discordance arose from sampling rather than the platform. For the remaining 28 patients, we confirmed the expression of native $A L K$ (Table 2, Fig. 3 and Supplementary Table 2 , see section on supplementary data given at the end of this article). We also assessed the presence of rearrangements of RET by Nanostring using probes that target the RET exonic imbalance or specific RET/PTC fusion junction. Out of 32 FFPE samples of BRAF WT papillary carcinoma, only one case exhibited the RET/PTC rearrangement (3.1\%, Supplementary Fig. 4). Although the number of samples was limited, these results indicate that $A L K$ and RET translocations are mutually exclusive as in the case of rearrangement of $A L K$ and $B R A F^{\mathrm{V} 600 \mathrm{E}}$ mutation (Kelly et al. 2014, Perot et al. 2014).

\section{Clinical characteristics of patients with papillary carcinomas that harbor rearrangements of $A L K$}

In this series of patients with papillary carcinomas with rearrangements of $A L K$, a distinct preference in terms of demographic factors or histological subtypes was not found (Table 2). All patients denied having a history of neck irradiation. Notably, the $S T R N-A L K$ rearrangement

was found in a young patient with solid variant papillary carcinoma. Patients with this variant are known to have a worse prognosis (Nikiforov et al. 2001). Patient 2, on the other hand, had small follicular variant papillary carcinoma, which is known to have a better prognosis. All four patients with rearrangement of $A L K$ showed favorable responses to the initial surgery with or without radioactive iodine ablation therapy.

\section{Discussion}

Analysis of thyroid tumor tissue archives revealed that approximately $1.5 \%$ of $B R A F$ WT papillary carcinomas harbor rearrangements of $A L K$. Our report is the largest study to date to report the frequency of rearrangements of $A L K$ in thyroid cancer. An estimated 40568 and 62980 new cases of thyroid cancer each year are diagnosed in Korea (Korea Central Cancer Registry 2011) and the USA (Siegel et al.2014) respectively. As a result, we extrapolated the number of patients with papillary carcinoma with rearrangements of $A L K$ to be 192 in Korea and to be 468 in the USA, assuming that $90 \%$ of all thyroid cancers are papillary carcinoma and that the $B R A F^{\mathrm{V} 600 \mathrm{E}}$ mutation rate of each country is 65 and $45 \%$ respectively (Kim et al. 2012). ALK is involved in the initiation and progression of many different cancer types (Mano 2012, Hallberg \& Palmer 2013), including lymphoma, neuroblastoma, and NSCLC. Preclinical studies in thyroid cancer patients (Kelly et al. 2014), indicated that rearrangements of $A L K$

Published by Bioscientifica Ltd. 
Table 2 Clinical and histological details of the four patients with papillary carcinoma with rearrangements of $A L K$

\begin{tabular}{|c|c|c|c|c|}
\hline & Patient 1 & Patient 2 & Patient 3 & Patient 4 \\
\hline Age (years) & 13 & 50 & 36 & 48 \\
\hline Sex & Female & Female & Male & Female \\
\hline History of neck irradiation & - & - & - & - \\
\hline Preoperative cytology & $\begin{array}{l}\text { Suspicious for } \\
\text { papillary } \\
\text { carcinoma }\end{array}$ & $\begin{array}{l}\text { Atypia of } \\
\text { undetermined } \\
\text { significance }\end{array}$ & $\begin{array}{l}\text { Suspicious } \\
\text { for papillary } \\
\text { carcinoma }\end{array}$ & $\begin{array}{l}\text { Suspicious for } \\
\text { papillary } \\
\text { carcinoma }\end{array}$ \\
\hline Surgery & TT with CND & TT with CND & $\begin{array}{l}\text { TT with ipsilateral } \\
\text { MRND }\end{array}$ & $\begin{array}{l}\text { TT with ipsilateral } \\
\text { MRND }\end{array}$ \\
\hline Tumor size $(\mathrm{cm})$ & 2.8 & 0.6 & 1.9 & 0.7 \\
\hline Histological subtype & Solid & Follicular & Classic & Classic \\
\hline Extrathyroidal extension & Microscopic & Microscopic & Microscopic & - \\
\hline Multifocality & - & - & - & + (bilateral) \\
\hline Lymph node metastasis & $0 / 7$ & $0 / 8$ & $2 / 13$ & $2 / 15$ \\
\hline Other pathology & $\begin{array}{l}\text { Lymphocytic } \\
\text { thyroiditis }\end{array}$ & $\begin{array}{r}\text { Lymphocytic } \\
\text { thyroiditis }\end{array}$ & $\begin{array}{r}\text { Lymphocytic } \\
\text { thyroiditis }\end{array}$ & $\begin{array}{l}\text { Lymphocytic } \\
\text { thyroiditis, } \\
\text { nodular goiter }\end{array}$ \\
\hline TNM staging & I (pT3N0) & III (pT3N0) & I (pT3N1b) & III (pT1aN1a) \\
\hline$B R A F^{\mathrm{V} 600 \overline{\mathrm{E}}}$ & WT & WT & WT & WT \\
\hline $\begin{array}{l}\text { Adjuvant radioactive iodine } \\
\text { ablation (cumulative dose) }\end{array}$ & ND & Ablated $(30 \mathrm{mCi})$ & Ablated (130 mCi) & Ablated $(60 \mathrm{mCi})$ \\
\hline Follow-up status (duration) & NED (17 months) & NED (24 months) & NED (30 months) & NED (34 months) \\
\hline \multicolumn{5}{|l|}{ Tests for $A L K$ rearrangement } \\
\hline $\mathrm{IHC}$ & ++ & ++ & + & + \\
\hline FISH & + & + & + & + \\
\hline Nanostring $\left(3^{\prime}: 5^{\prime}\right.$ ratio $)$ & $+(2.57)$ & $+(4.91)$ & $+(3.88)$ & $-(0.92)^{a}$ \\
\hline Fusion partner & STRN & STRN & Unknown & ND \\
\hline
\end{tabular}

CND, central neck dissection; MRND, modified radical neck dissection; ND, not done; NED, no evidence of disease; TT, total thyroidectomy.

aThe Nanostring result for patient 4 seemed to be a false negative, because the remaining amount of FFPE sample was insufficient after FISH and IHC analyses.

in thyroid cancers may also be sensitive to ALK inhibitors. Therefore, we expect that tumors with rearrangement of $A L K$ will become a unique, targetable subset of thyroid cancer and that identification of this emerging biomarker will have an effect on the diagnosis and treatment of patients with advanced DTC.

Diagnostic tests for identifying rearrangements of $A L K$ are important in clinical settings, as such tests can identify those patients who will probably benefit from a targeted therapy. Traditionally, FISH analysis using probes flanking the $A L K$ locus has been used for the identification of this rearrangement (Villamor et al. 2008); however, FISH may not be the optimal technique for routine practice due to the high cost and need for technical expertise. The break apart signal patterns resulting from the intrachromosomal deletion (STRN-ALK) and inversion (EML4-ALK) are often subtle and can easily be missed by this method (Mino-Kenudson et al. 2010). Alternatively, Japanese researchers extracted RNA from stored FFPE samples and used highly sensitive RT-PCR in conjunction with $5^{\prime}$ RACE to detect the presence of a high frequency of EML4-ALK rearrangements in papillary carcinomas from atomic bomb survivors (Hamatani et al. 2012).
In this study, papillary carcinomas with $A L K$ rearrangement invariably expressed an ALK protein that could readily be identified in the paraffinized samples using IHC with an ALK MAB. Indeed, no false FISH-negative cases were present in the four IHC-positive cases. As the rearrangement of $A L K$ results in loss of the transmembrane domain of ALK (Shaw et al. 2013), ALK IHC showed cytoplasmic staining in all of the rearranged cases. Given the wider availability and accuracy for detection of ectopic expression of ALK in the thyroid, we suggest that IHCbased screening should be used as a method for identifying thyroid cancer patients with rearrangements of $A L K$. As rearrangements of $A L K$ represent a potential therapeutic target and FISH is a validated method for the detection of actual fusions that correlate with the response to treatment, we recommend the use of IHC as a screening procedure and the use of FISH for the final confirmation of rearrangement of $A L K$. If a FISH assay is not available, the critical issue in clinical settings would be to quickly determine whether expressed ALK protein is activated or not, as some papillary carcinomas express WT ALK. In that case, additional use of antibodies against phosphorylated ALK would strengthen the IHC-based screening results, as

Published by Bioscientifica Ltd. 


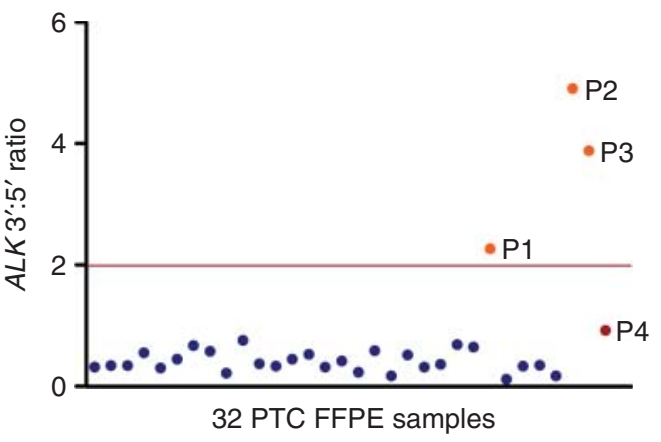

Figure 3

Nanostring results for $A L K$ rearrangement in 32 paraffinized samples of papillary carcinoma are documented as $3^{\prime}: 5^{\prime}$ ratio. The background threshold is indicated by a horizontal line. P1-4 indicates patients $1-4$ who have $A L K$ rearrangements. Other dots indicate patients with native $A L K$. A full colour version of this figure is available via http://dx.doi.org/10.1530/ ERC-14-0467.

the intensity of staining for phosphorylated ALK was correlated with the efficacy of subsequent crizotinib treatments in patients with NSCLC (Yang et al. 2014).

The frequencies of $A L K$ rearrangement in thyroid cancer have been reported previously (Hamatani et al. 2012, Kelly et al. 2014, Perot et al. 2014). Most recently, researchers from the University of Pittsburgh screened a tissue archive using RT-PCR and identified rearrangements of $A L K$ in four of 256 papillary carcinomas (1.6\%). These rearrangements included three STRN-ALK and one EML4rearrangements of $A L K$ (Kelly et al. 2014). None of the patients carrying rearrangements of $A L K$ harbored mutant $B R A F^{\mathrm{V} 600 \mathrm{E}}$ or had a history of radiation exposure. These investigators also reported an $S T R N-A L K$ rearrangement in a patient with anaplastic carcinoma adjacent to the follicular variant of papillary carcinoma. Although it remains to be determined whether $A L K$ is expressed in anaplastic carcinoma, a recent case report has described a remarkable response to crizotinib by a patient with anaplastic carcinoma and multiple lung metastases (Godbert et al. 2014).

The clinical profiles of patients with papillary carcinoma with $A L K$ rearrangement in this study were similar to those of patients with conventional $B R A F^{\mathrm{V} 600 \mathrm{E}}$-driven papillary carcinoma (Xing 2007, Kim et al. 2012) with the exception of one young patient who had a relatively large tumor with a solid variant. That patient preferred not to undergo adjuvant radioactive iodine therapy to avoid treatment-related morbidity in the future and maintained a disease-free status, precluding the necessity for further therapy at the time of submission of this manuscript for publication.
A relationship between radiation exposure and EML4-ALK rearrangement has been suggested in a previous report (Hamatani et al. 2012); however, subsequent studies, including ours, failed to identify an association between radiation exposure and rearrangement of ALK (Leeman-Neill et al. 2013, Kelly et al. 2014). The mutual exclusiveness of rearrangement of $A L K$ and the $B R A F^{\mathrm{V} 600 \mathrm{E}}$ mutation as well as with rearrangement of RET in this study is consistent with previous reports (Kelly et al. 2014, Perot et al. 2014) and supports the concept that rearrangement of $A L K$ is an independent driver in papillary carcinoma.

Given the high potential of receptor tyrosine kinases as therapeutic targets, systemic approaches are necessary in the future to identify activated kinase fusions. In our study, we explored Nanostring nCounter analysis as a systemic approach that can be multiplexed with as many as 800 different probes. In the Nanostring analysis, the specificity for $A L K$ fusion was $100 \%$, indicating its utility as a multikinase screening platform for thyroid cancer. Targeted next-generation sequencing (NGS) may also serve as an alternative multiscreening method (MacConaill 2013, Nikiforov et al. 2014). In recent years, NGS techniques capable of sequencing all known oncogenic drivers, including gene rearrangements, have been actively incorporated into clinical practice, and numerous clinical trials have been performed with the molecular targets identified. In thyroid cancer, $B R A F^{\mathrm{V} 600 \mathrm{E}}$ mutation and RET kinase fusions are known to be frequent genomic alterations (Nikiforov \& Nikiforova 2011), indicating that these kinases can serve as therapeutic targets in the face of failure of conventional treatment (Brose et al. 2014, www.clinicaltrial.gov; identifier number: NCT01876784).

The routine screening for rearrangement of $A L K$ for postoperative risk stratification in DTC may not offer a clinical benefit considering the low frequency of rearrangements of $A L K$ and the lack of a clear association between rearrangement of $A L K$ and poor clinical outcome of thyroid cancer. As there is no indication for targeted therapy in patients that showed good response to conventional treatment, the usefulness of screening of $A L K$ with respect to the clinical outcome of DTC should be sought in situations involving patients with advanced disease that is not manageable by surgery or administration of radioactive iodine. Interestingly, a recent prospective screening study has revealed that patients with rearrangements of $A L K$ in advanced NSCLC had improved overall survival with an effective targeted therapy than patient without rearrangement of $A L K$ after failure of at least one line of chemotherapy (Fallet et al. 2014).

Published by Bioscientifica Ltd 
A considerable body of evidence now supports the molecular phenotype-stratified approach to cancer care (Willyard 2013). In patients with radioactive-iodinerefractory thyroid cancer, the use of practical diagnostic methodology such as IHC to identify patients with rearrangements of $A L K$ is important not only for its immediate influence on care of individual patients but also for the recruitment of a responsive subgroup into a 'basket' trial.

\section{Supplementary data}

This is linked to the online version of the paper at http://dx.doi.org/10.1530/ ERC-14-0467.

\section{Declaration of interest}

The authors declare that there is no conflict of interest that could be perceived as prejudicing the impartiality of the research reported.

\section{Funding}

This research was supported by the Seoul National University Hospital (SNUH) \& the Seoul National University (SNU) College of Medicine Research Fund (grant number 800-20120032) awarded to W-Y Park.

\section{References}

Brose MS, Nutting CM, Jarzab B, Elisei R, Siena S, Bastholt L, de la Fouchardiere C, Pacini F, Paschke R, Shong YK et al. 2014 Sorafenib in radioactive iodine-refractory, locally advanced or metastatic differentiated thyroid cancer: a randomised, double-blind, phase 3 trial. Lancet 384 319-328. (doi:10.1016/S0140-6736(14)60421-9)

Chen AY, Jemal A \& Ward EM 2009 Increasing incidence of differentiated thyroid cancer in the United States, 1988-2005. Cancer 115 3801-3807. (doi:10.1002/cncr.24416)

Demeure MJ, Aziz M, Rosenberg R, Gurley SD, Bussey KJ \& Carpten JD 2014 Whole-genome sequencing of an aggressive BRAF wild-type papillary thyroid cancer identified EML4-ALK translocation as a therapeutic target. World Journal of Surgery 38 1296-1305. (doi:10.1007/s00268014-2485-3)

Edge SB, Byrd DR, Compton CC, Fritz AG, Greene FL, Trotti A (Eds) 2010 Thyroid. In AJCC Cancer Staging Manual, 7th edn, Ch 8, pp 87-96. New York, NY, USA: Springer.

Fallet V, Cadranel J, Doubre H, Toper C, Monnet I, Chinet T, Oliviero G, Foulon G, De Cremoux H, Vieira T et al. 2014 Prospective screening for $A L K$ : clinical features and outcome according to $A L K$ status. European Journal of Cancer 50 1239-1246. (doi:10.1016/j.ejca.2014. 02.001)

Fang DD, Zhang B, Gu Q, Lira M, Xu Q, Sun H, Qian M, Sheng W, Ozeck M, Wang Z et al. 2014 HIP1-ALK, a novel fusion variant that responds to crizotinib. Journal of Thoracic Oncology 9 285-294. (doi:10.1097/JTO. 0000000000000087)

Garcia-Gonzalez M, Abdulkader I, Boquete AV, Neo XM, Forteza J \& Cameselle-Teijeiro J 2005 Cyclooxygenase-2 in normal, hyperplastic and neoplastic follicular cells of the human thyroid gland. Virchows Archiv 447 12-17. (doi:10.1007/s00428-005-1235-1)
Godbert Y, Henriques de Figueiredo B, Bonichon F, Chibon F, Hostein I, Perot G, Dupin C, Daubech A, Belleannee G, Gros A et al. 2014 Remarkable response to crizotinib in woman with anaplastic lymphoma kinase-rearranged anaplastic thyroid carcinoma. Journal of Clinical Oncology [in press]. (doi:10.1200/JCO.2013.49.6596)

Hallberg B \& Palmer RH 2013 Mechanistic insight into ALK receptor tyrosine kinase in human cancer biology. Nature Reviews. Cancer 13 685-700. (doi:10.1038/nrc3580)

Hamatani K, Mukai M, Takahashi K, Hayashi Y, Nakachi K \& Kusunoki Y 2012 Rearranged anaplastic lymphoma kinase (ALK) gene in adultonset papillary thyroid cancer amongst atomic bomb survivors. Thyroid 22 1153-1159. (doi:10.1089/thy.2011.0511)

Kelly LM, Barila G, Liu P, Evdokimova VN, Trivedi S, Panebianco F, Gandhi M, Carty SE, Hodak SP, Luo J et al. 2014 Identification of the transforming $S T R N-A L K$ fusion as a potential therapeutic target in the aggressive forms of thyroid cancer. PNAS 111 4233-4238. (doi:10.1073/ pnas.1321937111)

Kim TH, Park YJ, Lim JA, Ahn HY, Lee EK, Lee YJ, Kim KW, Hahn SK, Youn YK, Kim KH et al. 2012 The association of the $B R A F^{\mathrm{V} 600 \mathrm{E}}$ mutation with prognostic factors and poor clinical outcome in papillary thyroid cancer: a meta-analysis. Cancer 118 1764-1773. (doi:10.1002/cncr.26500)

Kim H, Jang SJ, Chung DH, Yoo SB, Sun P, Jin Y, Nam KH, Paik JH \& Chung JH 2013 A comprehensive comparative analysis of the histomorphological features of $A L K$-rearranged lung adenocarcinoma based on driver oncogene mutations: frequent expression of epithelialmesenchymal transition markers than other genotype. PLOS ONE $\mathbf{8}$ e76999. (doi:10.1371/journal.pone.0076999)

Korea Central Cancer Registry; National Cancer Center 2011 National Cancer Statistics in Korea. http://ncc.re.kr/english/infor/kccr.jsp, accessed 26th April 2014.

Leeman-Neill RJ, Brenner AV, Little MP, Bogdanova TI, Hatch M, Zurnadzy LY, Mabuchi K, Tronko MD \& Nikiforov YE 2013 RET/PTC and PAX8/PPAR $\gamma$ chromosomal rearrangements in post-chernobyl thyroid cancer and their association with iodine-131 radiation dose and other characteristics. Cancer 119 1792-1799. (doi:10.1002/ cncr.27893)

Lira ME, Kim TM, Huang D, Deng S, Koh Y, Jang B, Go H, Lee SH, Chung DH, Kim WH et al. 2013 Multiplexed gene expression and fusion transcript analysis to detect ALK fusions in lung cancer. Journal of Molecular Diagnostics 15 51-61. (doi:10.1016/j.jmoldx. 2012.08.006)

MacConaill LE 2013 Existing and emerging technologies for tumor genomic profiling. Journal of Clinical Oncology 31 1815-1824. (doi:10.1200/JCO.2012.46.5948)

Mano H 2012 ALKoma: a cancer subtype with a shared target. Cancer Discovery 2 495-502. (doi:10.1158/2159-8290.CD-12-0009)

Mazzaferri EL \& Kloos RT 2001 Clinical review 128: Current approaches to primary therapy for papillary and follicular thyroid cancer. Journal of Clinical Endocrinology and Metabolism 86 1447-1463. (doi:10.1210/ jcem.86.4.7407)

Mino-Kenudson M, Chirieac LR, Law K, Hornick JL, Lindeman N, Mark EJ, Cohen DW, Johnson BE, Janne PA, Iafrate AJ et al. 2010 A novel, highly sensitive antibody allows for the routine detection of $A L K$ rearranged lung adenocarcinomas by standard immunohistochemistry. Clinical Cancer Research 16 1561-1571. (doi:10.1158/ 1078-0432.CCR-09-2845)

Nikiforov YE \& Nikiforova MN 2011 Molecular genetics and diagnosis of thyroid cancer. Nature Reviews. Endocrinology 7 569-580. (doi:10.1038/ nrendo.2011.142)

Nikiforov YE, Erickson LA, Nikiforova MN, Caudill CM \& Lloyd RV 2001 Solid variant of papillary thyroid carcinoma: incidence, clinicalpathologic characteristics, molecular analysis, and biologic behavior. American Journal of Surgical Pathology 25 1478-1484. (doi:10.1097/ 00000478-200112000-00002) 
Nikiforov YE, Carty SE, Chiosea SI, Coyne C, Duvvuri U, Ferris RL, Gooding WE, Hodak SP, LeBeau SO, Ohori NP et al. 2014 Highly accurate diagnosis of cancer in thyroid nodules with follicular neoplasm/suspicious for a follicular neoplasm cytology by ThyroSeq v2 next-generation sequencing assay. Cancer 120 3627-3634. (doi:10.1002/cncr.29038)

Park HS, Lee JK, Kim DW, Kulig K, Kim TM, Lee SH, Jeon YK, Chung DH \& Heo DS 2012 Immunohistochemical screening for anaplastic lymphoma kinase (ALK) rearrangement in advanced non-small cell lung cancer patients. Lung Cancer 77 288-292. (doi:10.1016/j.lungcan.2012. 03.004)

Perot G, Soubeyran I, Ribeiro A, Bonhomme B, Savagner F, BoutetBouzamondo N, Hostein I, Bonichon F, Godbert Y \& Chibon F 2014 Identification of a recurrent STRN/ALK fusion in thyroid carcinomas. PLOS ONE 9 e87170. (doi:10.1371/journal.pone.0087170)

Schlumberger MJ 1998 Papillary and follicular thyroid carcinoma. New England Journal of Medicine 338 297-306. (doi:10.1056/ NEJM199801293380506)

Shaw AT, Hsu PP, Awad MM \& Engelman JA 2013 Tyrosine kinase gene rearrangements in epithelial malignancies. Nature Reviews. Cancer $\mathbf{1 3}$ 772-787. (doi:10.1038/nrc3612)

Siegel R, Ma J, Zou Z \& Jemal A 2014 Cancer statistics, 2014. CA: A Cancer Journal for Clinicians 64 9-29. (doi:10.3322/caac.21208)

Suehara Y, Arcila M, Wang L, Hasanovic A, Ang D, Ito T, Kimura Y, Drilon A, Guha U, Rusch V et al. 2012 Identification of KIF5B-RET and GOPC-ROS1 fusions in lung adenocarcinomas through a comprehensive mRNA-based screen for tyrosine kinase fusions.
Clinical Cancer Research 18 6599-6608. (doi:10.1158/1078-0432. CCR-12-0838)

Swerdlow S, Campo E, Harris N, Jaffe ES, Pileri SA, Stein H, Thiele J \& Vardiman JW (Eds) 2008 In WHO Classification of Tumours of Haematopoietic and Lymphoid Tissues, 4th edn, Ch 11, pp 269-320. Lyon, France: IARC Press.

Vaisman F, Tala H, Grewal R \& Tuttle RM 2011 In differentiated thyroid cancer, an incomplete structural response to therapy is associated with significantly worse clinical outcomes than only an incomplete thyroglobulin response. Thyroid 21 1317-1322. (doi:10.1089/ thy.2011.0232)

Willyard C 2013 'Basket studies' will hold intricate data for cancer drug approvals. Nature Medicine 19 655. (doi:10.1038/nm0613-655)

Xing M 2007 BRAF mutation in papillary thyroid cancer: pathogenic role, molecular bases, and clinical implications. Endocrine Reviews 28 742-762. (doi:10.1210/er.2007-0007)

Yang JJ, Zhang XC, Su J, Xu CR, Zhou Q, Tian HX, Xie Z, Chen HJ, Huang YS, Jiang BY et al. 2014 Lung cancers with concomitant EGFR mutations and $A L K$ rearrangements: diverse responses to EGFR-TKI and crizotinib in relation to diverse receptors phosphorylation. Clinical Cancer Research 20 1383-1392. (doi:10.1158/1078-0432.CCR-13-0699)

Yi ES, Boland JM, Maleszewski JJ, Roden AC, Oliveira AM, Aubry MC, Erickson-Johnson MR, Caron BL, Li Y, Tang H et al. 2011 Correlation of IHC and FISH for $A L K$ gene rearrangement in non-small cell lung carcinoma: IHC score algorithm for FISH. Journal of Thoracic Oncology 6 459-465. (doi:10.1097/JTO.0b013e318209edb9)

Received in final form 5 November 2014

Accepted 19 November 2014
(C) 2015 Society for Endocrinology Printed in Great Britain 